\title{
SOBRE LA EXPERIENCIA DEL DERECHO EN BRASIL. JUSTICIA SOCIAL Y VIOLENCIA POLÍTICA*
}

\author{
Daniel Cefaï**
}

En los estudios sobre Brasil, el acento ha sido puesto millones de veces en el desarrollo del poder industrial, de la civilización urbana, de la movilidad social, del régimen democrático o en las distorsiones introducidas por las migraciones internas, el proceso de marginalización de la mayoría de la población, la proliferación anárquica de las favelas alrededor de las ciudades, la constitución de una economía informal a la sombra de las multinacionales, los estragos del analfabetismo, de la violencia, de la pobreza, de la dictadura. Pero los análisis en términos de "desarrollo del subdesarrollo" o de la "dialéctica de la dependencia" son de otro tiempo y la lectura de indicadores estadísticos o las construcciones de modelos económicos han encubierto frecuentemente ciertas consideraciones de historia cultural o de antropología política, sobre la eficacia de configuraciones simbólicas que mediatizan una experiencia social y política. De la misma manera, sin duda es insuficiente atenerse a una lectura politológica desde el punto de vista de las decisiones de la administración pública o del funcionamiento de las instituciones, de la regulación de la deuda interna y externa o de la crisis fiscal del Estado, para dar cuenta de las dificultades de la denominada "transición democrática", en lo que concierne principalmente a la realización de la idea de ciudadanía o la efectivización de las prescripciones del derecho.

Las cuestiones sobre el modo de reclutamiento de los funcionarios, de la falta de cohesión o del corporativismo de las administraciones, de la articulación entre los poderes ejecutivo, legislativo y judicial, de la interpenetración de las élites económica y política, del poder de los grupos de presión en el Congreso, de la fragilidad del sistema de partidos, son ciertamente de importancia capital para comprender cuál es la especificidad brasileña. No es menos necesario dirigir la atención en la experiencia del derecho y de la ciudadanía y, en contraposición a ella, sobre la experiencia de la violencia y de la desigualdad, en el espacio de la sociedad civil y de la sociedad política en tanto que ellas escapan a la jurisdicción del Estado, para calar de parte a parte ciertas características de las prácticas de tutela estatal y de la privatización política, de patronazgo y de clientelismo,

Traducción del francés: Gabriela Delamata/Ana Inés López-Accotto

(*) Este texto fue concebido en el marco del laboratorio de investigaciones en ciencias sociales Cidade e Cidadania de la Universidad de Sao Paulo y del Institute for Advanced Research de Sao Paulo. El financiamiento de la estancia por la obtención de una Bolsa de Investigación del Ministerio de Asuntos Exteriores de Francia.

**) Miembro del Laboratorio Ciudad y Ciudadanía, de la Universidad de Sao Paulo y del Centro de Sociología de las Prácticas y las Representaciones Políticas, de la Universidad de París VII-Jussieu. de nepotismo y de corrupción, de la denegación de la legitimidad de las reivindicaciones sociales o de los movimientos populares, o del bloqueo de la puesta en práctica de mecanismos de representación y de expresión pública.

En el texto siguiente intentaremos, sin caer en el folklore culturalista de un Brasil eterno, enunciar algunas hipótesis sobre la cuestión social y la cuestión de la violencia. Esta presentación debe mucho a nuestras discusiones con Maria-Celia PAOLI y Vera Silva TELLES, en el marco del laboratorio Cidade e Cidadania, de la Universidad de Sao Pablo'. Se esfuerza en mostrar que la violencia penal y la injusticia social no son solamente un producto de la lucha de clases o un efecto de la incompetencia del Estado: ellas remiten fundamentalmente -e independientemente de las estrategias de reproducción o de cambio del orden social por los actores-, a ciertas matrices de representaciones y de prácticas, a ciertos principios de moralidad o de legitimidad.

En el caso de la justicia social, las leyes han codificado una desigualdad jerárquica de cara a los "pobres" o el "pueblo", arrojando fuera del disfrute de los derechos del ciudadano a todos los individuos desprovistos de trabajo; en el caso de la violencia penal, la confusión de las categorías morales y legales y la insignificancia de los usos del Estado de Derecho, conducen a una perversión y a una transgresión de las leyes por parte de aquellos a los que les correspondería hacerlas respetar. En uno y otro caso, el recurso a los análisis en términos de racionalidad instrumental o de disfuncionalidad institucional nos parece insuficiente; ciertas características de la cultura política y de la cultura jurídica deben ser invocadas, para que tales hechos se vuelvan comprensibles.

\section{LA CUESTIÓN SOCIAL}

El déficit de legalidad y de publicidad mina el ejercicio de la justicia social, negada por el juego de las alianzas personales o pervertido por el sesgo de la tutela estatal. La noción de derechos sociales está ausente de los sistemas de protección y de retribución de orden privado, que son la parte de bienes de los

(1) M. C. PAOLI, Trabajadores e Ciudadana. Experiencia do mundo publico nao historia do Brasil moderno, en ESTADOS AVANZADOS. № Especial 100 Anos de República, 3/7. 1989; V. S. TELLES, tesis doctoral en sociologla: A Cidadania Inexistente: Incivilidade e Pobreza, USP, 1992 
trabajadores (faxineiras, dependientes, aprendices, boias-frias), todavía excluidos, en la práctica, de un orden de la legalidad que los ignora, en particular fuera de las grandes metrópolis del sur y del sudeste; mientras que el trabajo de los niños, protegidos por el reciente Código de menores, continúa suministrando contingentes de mano de obra barata y maleable, o la actualidad de las crónicas sobre historias de esclavitud de los nordestinos, atraídos por los fazendeiros de las enormes propiedades en la Amazonia, para desmontar la selva o cuidar de la ganadería sin salario y bajo amenaza de muerte. El derecho a la Seguridad Social (Previdência Social), la obtención de subsidio de desempleo (solamente por 3 meses) o el reembolso de bajas por enfermedad (en los hospitales públicos) son negados a todo individuo sin trabajo, por una perversión del dispositivo legal que concede los derechos a unos y se los sustrae a otros, operando en un mismo golpe una discriminación entre ciudadanos, produciendo y sancionando legalmente las desigualdades de hecho.

Las medidas del Estado Novo, después del periodo de laisser-faire represivo de la Republica Velha, han podido parecer, sin embargo, como revolucionarias y es todavía así como las personas ancianas recuerdan hoy el período Vargas. Según W.Guilherme dos Santos ${ }^{2}$, el concepto clave de la política socioeconómica de los años 30 es el de "ciudadanía regulada", "cuyas raíces se sitúan, no en un código de valores políticos, sino en un sistema de estratificación de ocupaciones, (que es) fijada por una norma legal. Dicho de otra manera, son ciudadanos todos los miembros de la comunidad que están localizables en una u otra de las ocupaciones reconocidas y definidas por la ley". Los criterios de atribución selectiva de la ciudadanía no son solamente de edad, de nacimiento, de filiación, de capacidad, sino primordialmente de actividad profesional. Los trabajadores rurales, los empleados temporales, los desocupados y todas las categorías no reglamentadas, son pura y simplemente excluidos de la legislación social, no existen jurídicamente. Una serie de dispositivos de integración y de exclusión viene a fijar esta separación: la ley de sindicalización para los profesionales, de 1931, subordina el derecho de presentar las demandas profesionales a la Junta de Conciliación y de Juicio a la afiliación en un sindicato; el derecho a licencias pagadas y a las ventajas sociales, así como a participar en las negociaciones colectivas, están condicionados por la pertenencia a un sindicato según la Constitución de 1934; mientras que la Carta de Trabajo, creada en 1932 y sancionada en 1937, de la cual depende la obtención de un nuevo empleo, valdrá hasta 1988 como documento tangible de ciudadanía, o "certificado de nacimiento cívico". La atribución de derechos por el mecanismo de una justicia procedimental, que regule la redistribución de bienes materiales y simbólicos, es así pervertida por una jerarquización de los individuos en función de su posición en el mercado de trabajo. El Estado controla la determinación del monto de los subsidios en relación a una escala de estratificación económica y se arroga el derecho de cortar el acceso al espacio político a los excluidos del salario, usando un dispositivo jurídico de igualación de las oportunidades sociales para reconducir a las desigualdades ya ancladas en las representaciones y las prácticas sociales. Finalmente, creando una alianza entre la oligarquía político-administrativa ligada al Ministerio de

(2) W. GUILHERME DOS SANTOS, Ciudadania e Justiça. A Politica Social na Orden Brasileira. Ed. Campus, Rio, 1979, en part. pp.71-82.
Trabajo y la oligarquía sindical a la cabeza de las organizaciones obreras, y prohibiendo toda forma de representación y de reivindicación exterior a los afiliados del sindicato público, el Estado bloquea toda veleidad de expresión autónoma de la sociedad.

Desde la promulgación de la Constitución de 1988, la legislación corporativa ha sido en gran parte desmantelada, pero la cláusula de una ocupación laboral está aun vigente: los derechos sociales están reservados a aquellos que pueden exhibir su carta de trabajo sin antecedentes penales y firmada (ter ficha limpa e carteira assinada). Por otro lado, numerosos análisis han desmontado los mecanismos de dilapidación corporativa de los recursos sociales en la autorreproducción de la máquina administrativa, de compra clientelar de votos por el camino torcido de la asistencia social en periodo electoral, o de desvío de los fondos públicos hacia las empresas de carácter privado; y descrito las distorsiones inducidas por los criterios de subsidios (enfermedad, vejez, invalidez, desempleo) que, indexados sobre el monto de las ganancias, terminan por alinearse sobre a estructura de las categorías salariales, y por privilegiar a las clases menos desprotegidas ${ }^{3}$.

No obstante, el problema de la pobreza no ha hecho más que crecer durante los años 80 , desplazándose de sus lugares de presencia tradicionales, "a los márgenes del mercado de trabajo, en el submundo de la economía informal, a los confines del mundo rural, en un nordeste de pesada herencia oligárquica" ${ }^{\text {, hacia los }}$ centros de la economía nacional, alcanzando a los trabajadores urbanos, incluso a los integrados al aparato industrial y beneficiarios de la legislación social, víctimas de la degradación de las remuneraciones salariales y de los servicios públicos. La demarcación entre sectores formal e informal, entre trabajadores y desempleados, entre obreros y autónomos, no es ya evidente y las capas más pobres, cuyo poder de compra fue laminado por la inflación y por la crisis, son siempre más tributarias de la precariedad de la vivienda (favelas e curtiços), del drama de la enfermedad (decadencia de los hospitales), sin hablar de la desnutrición crónica o del envejecimiento precoz. Pero la tematización de esos fenómenos como relevantes para la responsabilidad pública no está todavía a la orden del día. Muchas imágenes de la pobreza han sido señalados por V. S. Telles de la siguiente manera:

(3) Ver los trabajos del Núcleo de Políticas Públicas de Campinas; o A. SOBREIRA DE MOURA O Estado e as Politicas Publicas na Transiçao Democratica, Vértice, 1989. O las investigaciones sobre 1 importancia de la cuestión social en el régimen democrático de C. LEFORT, Democratie et représentationî. D. PECAUT, B. SORJ, Metamorphoses de la Représentation Politique au Brésil et en Europe, CNRS 991, pp.223-232.

(4) Investigación de V. SILVA TELLES, op. cit. Ver también A. ZALUAR, A Maquina e a Revolta, Brasiliense, 1985. Esta última señala la heterogeneidad de la noción de clases populares, pero mantiene su uso contra las categorizaciones de obrero manual o trabajador marginal. Esta noción permite reagrupar a la mayor parte de los habitantes de las ciudades, que pasan por la fuerza de las fluctuaciones de la economía de un estatus al otro (de empleado de la General Motors en Sao Paulo a revendedor ambulante

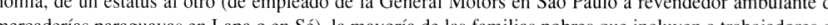

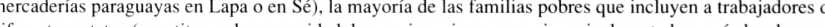
diferentes estatus (constituyendo una unidad de convivencia y supervivencia durante los períodos de vacas lacass.

El povao es el blanco de toda una serie de expresiones medio irónicas, medio despreciativas, y el rechazo fantasmático de las "clases medias". Oposición hecha entre "pessoas que se lavam, brancos, bo gente, medalhoes" (alusión a la teoría del medallón de Machado de Assis en Papeis Avulsos), y "gentinhas, zé-povinho, arraia-miuda, gentalha, massa" (ver R. Da MATTA, Carnavais, Bandidos, Herois, Rio, 1977), esos Joao-Ninguem, esos comedores de harina de tapioca (farofeiros), "esta población que habla travesado y que huele mal" (esse povao que fala errado e cheirra ruim). Sin dejar de eleva la queja hab atravesado y que huele mal" (esse povao que fala errado e cheirra rum). Sin dejar de elevar la queja sobre estas gen prometido desde siempre y entrevisto durante el milagro de los años 60 (esse povo é tao feio, tao atrasado; o pais no adianta com essa gente). Así los bellos barrios deben ser protegidos contra la amenaza de una invasión por la masa de los marginados, de los inservibles (marginais, vagabundos), multitud abyecta de criminales en potencia que, por no haber sido librados de su crasa ignorancia, deben ser vigilados y reprimidos permanentemente. 
- La imagen del gusto estético y de la reprobación ética: la compasión se encuentra sin respuestas ante esta masa indiferenciada de fealdad y miseria, marcada por el hecho de naturaleza: los pobres están infradotados en materia de belleza corporal y de viveza de espíritu, representación que va a menudo a la par con las consideraciones sobre la desigualdad entre las razas y los fantasmas sobre la africanización o la bolivianización de Brasil; y todos ellos culpables de pasividad: los pobres no hacen nada para salir de la pobreza, se contentan en procrear retahílas de niños, no aprenden a leer y a escribir, vegetan en sus tugurios por degeneración moral.

- La imagen de la fatalidad inevitable: isso é Brasil. La pobreza que se imputa cada vez menos a la rapacidad de los países del centro, que no se espera más erradicar mediante el progreso, deviene un elemento del paisaje. Prevalece la impotencia y el hastío ante un hecho social que no se alcanza a analizar racionalmente, a reflexionar históricamente, a identificar administrativamente, a transformar políticamente. Los contrastes riqueza/pobreza, modernidad/arcaísmo, forman parte de la esencia de la nación brasileña. El mal es banalizado, trivializado, desligado de toda atribución de responsabilidades, de toda expectativa de soluciones, hasta el punto de parecer natural.

- La imagen de la inquietud sorda y del control represivo: las clases peligrosas son estigmatizadas como factor de vicio y de crimen. El debilitamiento de los lazos familiares y de los vínculos de trabajo que hacen que un individuo ocupe su lugar. Sin casa ni hogar, sin fe ni ley: los pobres son irracionales e imprevisibles, irresponsables e inmorales. Estos discursos de patología social apelan a las prácticas de tratamiento profiláctico, donde los policías y justiceiros son los héroes y Gil Gomes o Anafasio Jazadji los heraldos ${ }^{5}$. Los escuadrones de la muerte exterminan así legítimamente a los ojos de una parte de la población a mendigos, loucos, crianças abandonadas, tarados sexuais, ladroes y criminosos. Tratamiento preventivo a la vez que curativo: la presunción de inocencia no vale para el pobre, culpable de oficio de costumbres disolutas, de una existencia vagabunda, de mezcla racial, de alcoholismo inveterado, de violencia gratuita, de retraso mental- tantas taras imputadas sin más garantía que la (supuesta) honestidad del que juzga.

Esas imágenes de la pobreza, como un estado de naturaleza objetivo o un estado de moralidad claudicante, no pueden esperar más que actos de caridad, dentro de la línea de la tradición de asistencia del Estado Novo, versión estatal de la "gestión filantrópica" de la miseria, o actos de violencia, en nombre de la seguridad pública que los representantes del orden deben asegurar contra esas hordas de desclasados ${ }^{6}$. En todo caso, la igualdad de derechos no vale para los despossuidos, destituidos, desprotegidos, marginalizados: el principio de isonomía ante la ley pesa poco frente al paternalismo autoritario y a la clasificación

(5) Gil Gomes y Anafasio Jazadji han desarrollado un estilo sensacionalista de crónica policial radiofónica y televisiva. Describen cotidianamente los últimos hechos sangrientos, con efectos melodramáticos de encuadre, montaje, prosodia, música, insistiendo en la omnipresencia del crimen y del vicio en la monstruosidad de los marginados en relación a las buenas gentes. Demagogia moralista, con la complicidad de la polićí que los autoriza a cealizar inerrogatorios a presun. Des en plicida de li policice los (6).Sobre estos dos modos de control y de adiestramiento de las "clases subalternas", ver las inves tigaciones en curso de Sergio ADORNO, y especialmente su reseña de fuentes: "A cruzada filantrópica: a asistencia social institucionalizada em Sao Paulo. 1880-1920", Dossier NEV, 1991, nº 1, USP. jerárquica heredada de la fazenda y del Estado Novo. Nada de darles estatus público: fuera del mercado de trabajo no hay existencia jurídica, representación sindical, derecho social, reivindicación colectiva. Es impensable que la pobreza encuentre un ámbito de expresión y se constituya un espacio de representación en el que los pobres sean reconocidos como ciudadanos provistos de derechos y semejantes en condición a los demás. En virtud de jerarquías simbólicas y de divisiones jurídicas bien establecidas, alentadas por las prácticas de distribución de los beneficios sociales, los pobres son a priori excluidos y se excluyen a sí mismos del derecho a tener derechos (Arendt). La pobreza, desplazada de los barrios caros por los precios disuasorios y las milicias privadas, está sin embargo omnipresente en la boca de los políticos o en las pantallas de televisión. Pero esta representación, más allá de la operación de naturalización o de moralización que encubre, va a la par con una pérdida de realidad': la cuestión es convertida en espectáculo, los reportajes sobre los sin techo (sem têto) o los niños ladrones (trombadinhas), se multiplican a fin de atemorizar a las buenas gentes y de alabar los servicios de la policía, a través de la dramatización de las informaciones sensacionalistas (por ejemplo la de Aqui Ago$r a^{8}$ ), o a fin de compadecerse con una cierta autocomplacencia masoquista de la decadencia del país, y dar cuerpo a la tonalidad dominante del pesimismo (baixo astral). Sobre el fondo de distensión de la responsabilidad pública, del rechazo de la cuestión política -y de la apelación a la caridad o a la compasión, sentimientos que no se pueden evitar.

Sólo recientemente, la cuestión social, incapaz de movilizar a una opinión pública poco adepta a los valores de la igualdad y de la justicia, ha ganado sus títulos de legitimidad política. Ha cesado de aparecer como el juego de especulaciones esclarecidas de intelectuales progresistas, que sentían la vocación de "modernizar la nación" y de "educar al pueblo" -proyecto común a los positivistas, a los modernistas, a los integristas o a los marxistas. Se desmarca de ser objeto de tratamientos técnicos por parte de un estado paternalista y bien intencionado, que concede una "ciudadanía regulada" arrojando a los no trabajadores a los márgenes de la inexistencia cívica y negando toda existencia a la sociedad civil. No se refiere más, finalmente, a una relación filantrópica del orden de lo privado o de lo personal o a una relación clientelista de protección y de sujeción, ciegas a toda dimensión del interés general, del bien público o de la justicia social. Tales cuestiones han acabado por ser puestas

7). V.SILVA TELLES, op. cit. Esta hipótesis de la pérdida de realidad y de la ausencia de responsabilidad no debe ser leída en términos de distorsión ideológica: debe, sobre todo, interpretarse por la incapacidad de los ciudadanos para remitirse a los principios comunes de igualdad y de justicia, en relación con la exacerbación de las relaciones interpersonales en un mundo jerárquico (cordialidad), y a la inexistencia de un referente republicano hacia el bien público (patrimonialismo). Ver las interpretaciones pioneras, y todavía actuales de S. BUARQUE de HOLANDA, Raizes do Brazil, José Olympio, 1986 (1936). (8). Aqui Agora es un progra de televisión de la SBT, cadena de Silvio Santos, emitido cotidia(8). Aqui Agora es un programa de televisión de la SBT, cadena de Silvio Santos, emitido cotidianament de 18.30 a 20 , y explicitamente concebido para las "clases populares": se auto-titula $O$ jornal do poro, a arma do poro. El estilo enfatico, los reportajes de estilo cortado, el ritmo rapido, los comentarios moralizantes, los presentadores célebres tales como Maguila, un anciano boxeador, promovido a comentarista económico...Aqui Agora, que conoce un éxito creciente, entremezcla: flashes internacionales (temblores de tierra, incendios, catástrofes naturales: "nadie escapa a su destino", "todos los hombres son iguales ante la desgracia"): reportajes religiosos (milagros, peregrinaciones, umbandas, candombles, exorcismos, santos locales, deseos realizados); temas tradicionales (foothall. Fórmula I, Nordeste, rodeios do peao hoiadeiro, fofocas da coluna secial); crónicas policiales (Gil Gomes): consejos en inversiones a fumean him (fundao, poupansa, vulgarización de las informaciones sobre inflación, orientación de la economia en el
día a día); sin olvidar el discurso de defensa de la moralidad pública y de drenaje del descontento político (inseguridad de los barrios, robo a los ancianos, degradación de las condiciones de vida, casos de corrupción o de nepotismo) 
en el horizonte abierto por una nueva dinámica de la acción colectiva y de la expresión pública, distanciada del privatismo y del estatismo. Las reivindicaciones de los movimientos populares, en particular por la salud (creación de puestos asistenciales en los arrabales por la acción de los Movimentos de Bairro, asociaciones de barrio) y por la vivienda (ocupación de terrenos para los sem-casa, los sin casa y los sem-têto, los sin techo), asî como los conflictos de propiedad en el campo entre pequeños agricultores y grandes propietarios sostenidos por los sindicatos rurales y las comunidades eclesiásticas coordinadas a escala nacional, impusieron una nueva relación de los ciudadanos con el derecho y de la sociedad respecto al estado, y una nueva representación de problemas hasta ahora privados y en adelante públicos.

El despliegue de espacios públicos donde se forman y enfrentan las opiniones públicas y donde los intereses colectivos se mediatizan a través de la negociación entre actores colectivos, era inédito en Brasil -con excepción del intermedio de 1945, al final de la era Vargas, hasta 1964, cuando el golpe de estado de los militares clausuró un período de agitación sindical mediante la supresión de todas las libertades públicas. Demás está decir que la "transición democrática" ha sido el emblema, casi hasta transformarse en mito, de la invención y del descubrimiento de un horizonte autónomo de la sociedad. El estado antes de 1930 no era más que un apéndice de los latifundios senhoriais, grandes plantaciones cuyos propietarios se burlaban de que la "ley del Estado" no franqueaba la puerta de sus fazendas. Patriarcas, coroneles, esclavistas de alma, la cosa pública no era a sus ojos más que una cuestión de asuntos domésticos, la cuestión social se reducía a un vulgar problema de policía. Por consiguiente, el liberalismo brasileño no ha sido nunca más que un discurso de defensa de los intereses privados ${ }^{9}$ : rechazo del intervencionismo estatal pero también desprecio por los derechos económicos y sociales, por la libertades individuales y públicas y la incapacidad de pensar un dominio de la res publica que trascienda los límites de los intereses privados. Inversamente, la promoción por Vargas del Estado Novo, a partir de 1937, significó la adaptación de un sistema organicista y corporativo más o menos inspirado en el modelo musoliniano. La cuestión social fue, dentro del mismo movimiento, reconocida y rechazada por el establecimiento de una legislación sindical y social que, a la vez, delimita un lugar en la sociedad, el de los ciudadanos poseedores de un trabajo y, como tales, portadores de derechos y de deberes y de la misma forma coloca ese lugar de la sociedad bajo la tutela del Estado al prohibir el pluripartidismo y al imponer un sindicato único.

Este blindaje regirá la relación entre el Estado y la sociedad hasta 1976, fecha de la creación del MDB frente a la progubernamental ARENA y después, en 1979, fecha de la creación del PT que reagrupó tanto a los miembros de las comunidades eclesiásticas de base, como a los tránsfugas del MDB y los grupúsculos izquierdistas o los representantes de movimientos populares y de organizaciones obreras y campesinas. Ese mismo año, el mono-

(9).Sobre el liberalismo, ver W. GUILHERME DOS SANTOS, "A praxis no Brasil: porpostas para una reflexao e pesquisa", en Ordem Burguesa e Liberalismo Politico, Duas Cidades; SP, 1978; R. FAORO, "Existe um pensamento politico brasileiro?", ESTUDOS AVANCCADOS, VOL 1, № 1, 1987, pp. 958; A. BOSI "A escravidao entre dois liberalismos", ESTUDOS AVACADOS, vol. 2, no 3, pp. 4-39; o ] MARQUES PEREIRA "F M Brasil, 1987. élites jurídicas y políticas de la época: S. ADORNO, Os aprendizes do Poder. O Bacharelismo Liberal n Politica Brasileira, Paz e Terra, 1988, Sin olvidar S. BUARQUE de HOLANDA, op. cit., p.119: "L'idéologie impersonnelle du libéralisme démocratique ne s'est jamais naturalisée parmi nous". polio del sindicato estatal fue puesto en cuestión en la CUT, después de las huelgas de los metalúrgicos de Sao Bernardo, por mil y una maniobra de reinterpretación y de reajuste del marco de la legislación en vigor; en fin, este aprendizaje del "derecho a tener derechos" y del deber de asumir sus deberes, de la dinámica del conflicto y de la representación, de la reivindicación y del reconocimiento, ha desembocado en la sanción constitucional de nuevos derechos laborales y sociales en 1988.

\section{VIOLENCIA Y DERECHO}

Una simple fenomenología de la vida cotidiana nos enfrenta a la "ley del más fuerte": desde que se sale de la órbita de la esfera doméstica o del registro de la intimidad o de la cordialidad, los testimonios sobre violencia ordinaria se multiplican. Las clases medias contra el povao, los blancos contra los Indios y Negros, los hombres versus las mujeres y los adultos versus los menores, los patrones contra los empleados y los fazendeiros contra los boias-frias, los heterosexuales contra los homosexuales (los machoes contra los bichinhas), los urbanitas contra los campesinos (caipiras), los automovilistas contra los peatones (pedestres). La violencia simbólica, del orden del desprecio manifiesto o de la broma equívoca, pero también violencia real: El número de personas muertas o heridas por el tráfico es del orden de varias decenas de miles en cada Estado. Ciertos reglamentos del Código de Circulación no están visiblemente arraigados, tal que el respeto a las luces de señalización o a las vías de circulación y las infracciones no son de ninguna manera verbalizadas por los policías, más preocupados por recibir una propina que por hacer respetar la ley. El tráfico en la Marginal Tietê de Sao Paulo o en la Avenida Brasil de Río, parece una metáfora del capitalismo salvaje, del liberalismo agresivo en vigor en las otras esferas de actividad.

- Los niños y los adolescentes abandonados son el blanco de los grupos de exterminio (Esquadroes da Morte, justiceiros de bairro), sostenidos y financiados por los pequeños comerciantes contra el robo, por los conductores de taxis contra la agresión, y apoyados por ciertos policías fuera del tiempo de servicio. En Río, las mafias de narcotraficantes, que suplantan lenta pero seguramente a las mafias tradicionales de la lotería (jogo de bicho), después de desmantelar las fuentes de producción y de circulación de la cocaína en los países vecinos, los utilizan como vigilantes, guías o traficantes y los eliminan al mínimo desacato.

- La destrucción de los lugares naturales en la Amazonia, está acompañado por el genocidio de los pueblos Indios del entorno, los cuales son primeramente reducidos a mendicidad, a través del juego de los intercambios con los buscadores de oro (garimpeiros) que les aparta poco a poco de sus prácticas culturales; después son amenazados y atacados por cuestiones de delimitación territorial por los agricultores colonizadores de Para o de Roraima; y, luego aniquilados por la disentería, la tuberculosis, el cólera o el SIDA, que diezma a dos tercios de la población de las aldeas.

- Mientras que los conflictos de la tierra en el campo han sido, según cifras de la Comissao Pastoral da Terra (CPT), confirmados por el Nucleo de Estudos da Violencia de la Universidad de Sao Paulo, y por el Instituto de Apoio Juridico Popular de Río, el origen de 1565 asesinatos entre 1964 y 1989 (entre los 
cuales estuvo el de Chico Mendes), dio lugar a apenas 17 juicios y 8 condenas ( 3 sacerdotes, 3 abogados, 2 Indios, en los asuntos que se benefician por su resonancia nacional e internacional), la impunidad muestra de forma evidente la complicidad de los fazendeiros, de los policías, de los jueces, y de los políticos del interior del país; y no son más que la parte emergente de todas las amenazas, los golpes, las torturas y el esclavismo censados por los sindicatos de defensa de los camponeses y por las asociaciones de los derechos del hombre.

Podríamos prolongar ad nauseam esta lista fúnebre pero preferimos concentrarnos en la violencia policial. Los excesos de la policía son la regla: el método de sospecha sistemática, los usos de la violencia corporal, el desprecio por el derecho elemental de habeas corpus forman parte del "combate contra el crimen" mantenido cotidianamente. Los formalismos jurídicos son juzgados como demasiado sofisticados y demasiado ineficaces para el hampa: el encadenamiento de la inculpación y del proceso debe dejar lugar al jogo duro. La lógica simbólica de discriminación y criminalización, de estigmatización y de marginación de las “clases populares", es lo que se persigue aquí, y opera un división entre los "pobres pero honestos", "pobres pero honorables", portadores de las características de ser limpo, boa educaçao, fino trato, ser legal y la masa de los sem veira nem eira, fuente de problemas y de peligros, blanco de una represión preventiva, profilaxis moral, y de una intervención disciplinaria, violencia ortopráctica. Del lado de las "clases populares" la experiencia de la ciudadanía es la de las rondas y arrestos policiales (rondoes e arrastoes), la de la prisión sufrida como aleatoria o del juicio visto como arbitrario ${ }^{10}$. Los rituales del tribunal judicial, la retórica del Código Penal, no pueden ser más misteriosos y la referencia a la Ley tiene más que ver con la privación de la libertad que con la defensa de las libertades. Los derechos no son más que obligaciones impuestas de manera represiva y se confunden con el garrote policial y el enclaustramiento en la prisión. La experiencia estrictamente personal que fracasa en convertirse en palabra pública, se vive como soledad y como impotencia; y que atormenta por el miedo de ir a prisión sin razón, activado por los discursos sobre la inseguridad y las intervenciones policiales.

Estas estrategias de intimidación y de inquisición están en vigor desde finales del siglo XIX": siempre a hecho falta "controlar a las clases peligrosas" y "suprimir a los elementos criminales", "someter a los revolucionarios", más adelante "detectar los comunistas". El objetivo fue ya reconocido en los años 20 , con la constitución de fichas de indeseables por parte de las asociaciones patronales, sustituida por la lucha contra la infiltración de los agitadores sociales, en particular los anarco-sindicalistas, a través de la creación de la Delegacia da Orden Politica e Social, en 1924, bajo la Republica Velha y continuada después bajo el Estado Novo, con la instauración de una legislación de excepción, la instalación de un Tribunal de Segurança Nacional y las medidas del corporativismo sindical. Este régimen de violencia omnipresente ha tenido su apogeo bajo la dictadura en la que, en nombre de la Ley de Seguridad Nacional (Lei de Segurança Nacional) y de la lucha contra el "enemigo interior", bajo la figura de la disidencia armada o del terrorismo guerrillero, se centralizó la policía bajo el alto mando de la armada (Decreto- ley № 667, 02/07/69), se crearon las unidades especiales como la ROTA o la Tatica Movel, se instauró una justicia interna corporis de la Policía Militar (enmienda constitucional № 7/1977, ¡ratificada por el Tribunal Supremo Federal!) y se levantó la barrera entre el derecho común y el criminal político. Esta institucionalización de la arbitrariedad amplificó los usos consagrados y tolerados de la violencia, desarrolló el recurso a los interrogatorios, desapariciones, torturas, ejecuciones, e instauró una lógica del terror en nombre de la "guerra permanente" contra la oposición social -sin que la maquinaria se embale como en Argentina o en Chile, quizás a causa del poco dinamismo de una sociedad ya saturada por una violencia y poco curtida en la contestación y en la reivindicación.

La dureza de la dictadura se relaja después de 1975, pero la violencia policial, si bien ha perdido en intensidad y en focalización política, sin embargo no ha cambiado de estatus. La relación anormalmente elevada entre el número de civiles muertos y el número de civiles heridos por la policía (2384/1008, entre 1982-1987, en el Estado de Sao Pablo, contra 481/147, en Nueva York, entre 1981-1985) o entre el número de civiles muertos y el número de policías muertos (2384/237, en Sao Pablo, o sea una ratio superior al $10 \%$ contra una ratio de $7,8 \%$ aproximadamente, en Nueva York) $)^{12}$, indica que la mayor parte de los disparos de la policía son deliberados y a sangre fría y no entran en las categorías de la defensa o la urgencia. No hay nada accidental en el récord establecido por la ROTA, sección especial que no cuenta más que con un efectivo de 700 hombres, que consiguió abatir a 129 civiles durante los primeros nueve meses de 1981. Las policías disfrutaron de un poder cuasi-discrecional, y de una cuasi-impunidad ante las leyes civiles. La imagen del policía por encima de la ley está sostenida por resto del sentido común, y el buen comisario es un buen pistoleiro que no vacila en hacer fuego, y un buen dador de pancadas (tradicionalmente con la palmatoria). Las batidas policiales, sin mandato legal, en los barrios populares no sorprenden a nadie: la cuestión social es, ante todo, "asunto de la policía"; igual que el hecho de que la ley reserve las prisiones especiales a los inculpados que poseen un título universitario, es algo que va de suyo: ¿Cómo mezclar un bacharel con los asaltantes o las prostitutas o con esas gentes de baja extracción? No hay más igualdad ante la ley que la que hay ante la violencia. Policia de gente para unos y policia de moleque para los otros.

La categorización que preside a estas diferencias de tratamiento es profundamente moral. El comisario en los puestos de policía (delegacias) de barrio aparece como el batidor del crimen y del vicio, el protector de las buenas costumbres y es a menudo percibido como el símbolo de la autoridad, si no bajo la figura de Padre. Es él quien hecha una bronca al marido violento o al niño revoltoso, quien arregla las peleas del vecindario y distribuye los "certificados simbólicos" de buena conducta a las gentes honestas. La relación ciudadano cívico/Estado se transforma en relación moral personalcensor: la mediación del derecho es cortocircuitada por la actitud paternalista, el consejo personal, la relación protectora y pro- 
veedora de seguridad ${ }^{13}$. El registro de las relaciones interpersonales se infiltra hasta en la forma de administrar la vida de la comisaría: los dosiers de denuncias o de investigaciones son ellos mismos supeditados a la buena voluntad del comisario, quien puede acelerar o retrasar el curso del asunto, cuando no es el escrivao, en los casos de menor importancia, a quien corresponde, según el monto de la propina, orientar las investigaciones en una dirección más o menos favorable, acortar o diferir los plazos de transmisión al tribunal. Manifestar cordialidad, tener buenas relaciones, ser bien educado, intervenir en el buen momento, prevalecen sobre la aplicación de la ley y el respeto de los reglamentos -mientras que a los ojos de los más desfavorecidos, es el comisario quien juzga la culpabilidad y decide el encarcelamiento: la iniciativa de apelar ante los tribunales es extremadamente rara entre los más pobres. De todas maneras, esta distorsión de la percepción de las instituciones policiales y judiciales no es tan infundada, las quejas de lentitud y carestía, de lejanía y de corrupción que se le hacen, se verifican a menudo. Y la intervención del comisario es preponderante en el manejo de las investigaciones, la recolección de las declaraciones, la presentación de los índicios, el registro de los testimonios, la transcripción de los hechos, la descripción de las acciones, la imputación de los motivos, la designación de los sospechosos. En cada una de estas operaciones de codificación del presunto delito, de la supuesta falta, lo mismo que en las decisiones de "arresto para interrogatorio", de "detención para verificación", el análisis de los procesos verbales testimonia el hecho de que la subsunción bajo las categorías jurídicas, a partir de las cuales será determinada la culpabilidad o la inocencia del acusado, se ıecubre con la subsunción bajo las categorías morales, operaciones de tipificación que prejuzgan en términos de bien y de mal, de justo y de injusto, de normal y de patológico, de inofensivo y de peligroso. Y más allá, lo que se produce en este choque es una transformación de las formas de juicio en vigor en el mundo privado, y más o menos organizadoras del vínculo civil, en formas de juicios válidos en la esfera del Derecho, y operan las distorsiones hasta en la interpretación de los códigos jurídicos o en el desarrollo de los procesos judiciales. La confusión entre público y privado, y entre moral y legal, que estaba ya consagrada por la legislación social, se encuentra presente en los usos del derecho penal. La arbitrariedad de la estigmatización y de la discriminación no es esta vez incorporada al dispositivo jurídico, sino que es parasitaria de las divisiones simbólicas del sentido común. Mientras que la correlación estadística establecida entre índices de criminalidad y pertenencia a las clases populares da, sin duda, menos cuenta de los efectos del desarraigo urbano y de la miseria material, que de los modos de intervención de la policía en el espacio social, y de los modos de recuento y de clasificación de las informaciones por los criminólogos ${ }^{14}$. El crimen organizado (jogo de bicho, narcotráfico) y los crímenes de cuello blanco (malversación de fondos públicos, operaciones financieras ilícitas...), "a la vista de los cuales los crímenes comunes contra el patrimonio son bromas" ${ }^{15}$, son dejadas de lado; y la represión sistemática y permanente contra los habitantes de los barrios populares está ausente en los buenos barrios, si no es con la finalidad de defender la propiedad privada o la paz dorada de los privilegiados, situación sin duda universal, pero totalmente caricaturesca en Brasil.

La violencia policial testimonia un trato hacia el derecho y un trato hacia lo social que no son privativos de la profesión, sino muestras del sentido común. La desconfianza frente al orden de las leyes, la deficiencia de las prescripciones de la ciudadanía, la confusión de las dimensiones de lo público y de lo privado, se redoblan en las dimensiones de lo legal y de lo moral; la criminalización de las clases populares y la estigmatización de los pobres y de los marginales remiten, más allá de toda determinación sociológica, a los sistemas de representaciones y de prácticas que orientan la relación entre personas y entre grupos. Un último fenómeno es sintomático de una cierta idea de la justicia, de acuerdo con las configuraciones simbólicas ya descriptas. Los linchamientos y las palizas colectivas llenan regularmente las columnas de la prensa y de los telediarios: una investigación efectuada entre septiembre de 1979 y enero de 1982 reveló 75 linchamientos ( 32 cumplidos, 43 intentados; 34 en Rio-Baixada Fluminense, 15 en el Estado de San Pablo), con 7 intervenciones de la comisaría o del tribunal, principalmente en los casos de inculpación por ataque contra residencias privadas o establecimientos comerciales, donde las víctimas son mayoritariamente adolescentes y miserables, y solamente 2 casos en las favelas urbanas donde las relaciones de vecindad y la organización de las comunidades apelan a otras formas de ajuste de cuentas ${ }^{16}$. Diferentes reportajes han demostrado que estos linchamientos eran una ocasión de venganza contra los vagabundos y los violadores, una manera preventiva de "limpiar el barrio" y, sobre todo, que ellos son vividos como un modo de ejercicio de la "justicia popular", testimoniando la falta de confianza en las instituciones legales de policía y de justicia. "El bandido debe morir y nada más" (Bandido tem mesmo é que morrer), y esta regla no es nunca mejor seguida que cuando se hace "justicia con las propias manos" (fazer justiça com as proprias maos). La furia punitiva, los grito de pega, mata, lyncha, se autojustifican después en nombre de Dios o de la Naturaleza contra los demonios y los monstruos, se limita en general a una carrera persecutoria y a un asesinato sumario, pudiendo acompañarse de lapidación, mutilación, castración, cremación y descuartizamiento.

Los conductores de taxi de Curitiba han puesto en movimiento un simulacro de investigación, de proceso, de defensa, antes de pasar a la ejecución, difiriendo la venganza inmediata y evaluando la pena a infligir por un redoblamiento mimético de los procedimientos oficiales. La ley del talión ha jugado contra la de los tribunales, el veredicto de culpabilidad y de horca había sido visto con anticipación. Pero los rodeos de la puesta en escena, más allá de la dimensión simbólica de eliminación de taras morales sin otra forma de proceso, valen como garantía de salvaguarda contra la incuria de la justicia. Los autores de la exacción no se molestan en disimular, beneficiándose de las manifestacio-
(13) R.KANT de LIMA, "A tradiçao inquisitorial", Revista Brasileira de Ciencias Sociais, ANPOCS, 1987. (14) A.L.PAIXAO, "Crime, controle social, e consolidaçao da democracia: as metaforas da democracia”, en F. W. REIS, G. O'DONNELL, A democracia no Brasil: dilemas e perpectivas, Vertice, SP. 1988, pp. 168-199.

(15) M.C.PAOLI, op. cit.; R. M. FISCHER, O Direito da Populaçao a Segurança, Vozes, Petropolis, 1985; R. M. FISCHER, Cidadania e Violencia Urbana, CEDEC, Petropolis, 1985; R. BOSCHI, Violencia e Cidade, Zahar, Rio, 1982.
(16) M.V.BENEVIDES, en Linchamentos, a partir de una investigación llevada a cabo entre septiembre de 1979 y enero de 1982, invoca como "factores de explicación": la situación de anomia de la comunidad, el sentimiento de inseguridad generalizada, el descrédito de las instituciones estatales, la interiorización de la violencia policial (así, el caso de Curitiba, donde un proceso simulado ha tenido lugar después de una sesión de torturas y de confesiones). 
nes de apoyo y de solidaridad de la población, gozando de la impunidad si no de la colaboración de las fuerzas de policía y reciben incluso algunas veces las felicitaciones de los consejeros municipales por haber defendido el "honor de la ciudad".

El sentimiento de inseguridad generalizada, el descrédito de las instituciones estatales y sobre todo la ignorancia del signifi- cado de las leyes que trascienden las acciones y las pasiones humanas, y la prisa por ajustar cuentas a los individuos percibidos como seres inmorales, más que como ciudadanos responsables de actos ilegales -todo eso da cuenta del cortocircuito de las mediaciones jurídico-judiciales, tenidas por inoperantes e injustas, "del lado de los bandidos".

\section{RESUMEN}

La cuestión social y la violencia política son problemas profundamente arraigados en la cultura brasileña. El autor analiza como éstos se reproducen en el cotidiano a partir de prácticas sociales, algunas amparadas jurídicamente, que despojan de los derechos de ciudadanía a los sectores populares marginados del mercado laboral formal.

\section{ABSTRACT}

Political violence and the social question are deeply rooted in brasilian culture. The author analyzes how these problems are reproduced through social practices in everyday life, some of them being juridically protected and stripping off elemmental rights of citizenship from the popular sectors, excluded from the formal labour market. 